\title{
Correction to: Organometallics in Process Chemistry: An Historical Snapshot
}

Vilvanathan Sivakumar, Rahul A. Watile, and Thomas J. Colacot

\section{Correction to:}

Chapter "Organometallics in Process Chemistry: An Historical Snapshot” in: V. Sivakumar et al., Topics in Organometallic Chemistry, DOI: 10.1007/3418_2019_34

On page 1, the line: "Affiliation at time of publication" is added above the current affiliation of Dr. Thomas: MilliporeSigma (a division of Merck KGaA), Milwaukee, WI, USA, and on page 17, the image of Keith Fagnou is removed. 